\title{
Tingkat Pengetahuan Dan Perilaku Swamedikasi Nyeri Menstruasi (Dismenore) Pada Siswi SMAN 1 Kajen Kabupaten Pekalongan Tahun 2021
}

\author{
Nofi Afiatus Sa'adah ${ }^{1}$, St. Rahmatullah ${ }^{2 *}$, Yulian Wahyu Permadi ${ }^{3}$, Ainun \\ Muthoharoh $^{4}$ \\ 1,2,3,4 Program Studi Sarjana Farmasi, Fakultas Ilmu Kesehatan, Universitas Muhammadiyah \\ Pekajangan Pekalongan, Indonesia \\ *email:amma88.an@gmail.com
}

\begin{abstract}
Self-Medicating is an activity that carried out to prevent the onset of a disease and treat mild symptoms or diseases by using drugs without medical supervision. Self-medicating will be useful if correctly based on sufficient knowledge of the selection. The aims of this study was to determine the level of knowledge and behavior of self-medicating for menstrual pain (dysmenorrhea) majoring in social and language at Senior Hight School Kajen Pekalonga. The method is this study used cross sectional method with 162 students with purpose sampling technique and questionnaire as a data retrieval tool. Data was analyzed by testing Spearman's Rank Correlation using Statistical Package for the Social Science version 16. The results of this study showed that the majority of respondents had a good level of knowledge about sel-medicating menstrual pain (dysmenorrhea) with total of 110 respondents (67.9\%) and the behavior showed that majority of respondents had good self-medicating behavior of menstrual pain (dysmenorrhea) with the number of 111 respondents (58.5\%). The conclucion of this study showed a relationship between the level of knowledge to selfmedicating behavior for menstrual pain (dysmenorrhea) in students of Senior High School Kajen Pekalongan with a correlation value of 0,184 .
\end{abstract}

Keywords: Menstrual pain; self-medication; high school student

\begin{abstract}
Abstrak
Swamedikasi merupakan suatu kegiatan yang dilakukan guna mencegah timbulnya suatu penyakit dan mengobati gejala atau penyakit yang ringan dengan menggunakan obat-obatan tanpa pengawasan medis. Swamedikasi akan bermanfaat apabila dilakukan dengan benar berdasarkan pengetahuan yang cukup tentang pemilihan dan penggunaan yang digunakan.Tujuan dari penelitian ini yaitu untuk mengetahui tingkat pengetahuandan perilaku swamedikasi nyeri menstruasi (dismenore)siswi jurusan IPS dan Bahasa SMAN 1 Kajen Kabupaten Pekalongan. Metode yang digunakan dalam penelitian ini yaitu metode cross sectional dengan responden yang berjumlah 162 siswi. Dalam penelitan ini teknik pengambilan sampel yang digunakan adalah dengan purpose sampling dan kuesioner sebagai alat pengambilan data. Analisis data dengan cara uji Korelasi Spearman's Rank menggunakan Statistical Package For the Sosial Scienceversi 16. Hasil penelitian ini pada tingkat pengetahuan menunjukkan bahwa mayoritas responden memiliki tingkat pengetahuan sangat baik tentang swamedikasi nyeri menstruasi (dismenore) dengan jumlah responden $110(67,9 \%)$ dan pada perilaku menunjukkan bahwa mayoritas responden memiliki perilaku swamedikasi nyeri menstruasi (dismenore) yang baik dengan jumlah responden $111(58,5 \%)$. Kesimpulan pada penelitian menunjukkan adanya hubungan antara tingkat pengetahuan terhadap perilaku swamedikasi nyeri menstruasi (dismenore) pada siswi SMAN 1 Kajen Kabupaten Pekalongan dengan nilai korelasi sebesar 0,184.
\end{abstract}

Kata kunci: Nyeri menstruasi; swamedikasi; siswi SMA 


\section{Prosiding Seminar Nasional Kesehatan 2021 Lembaga Penelitian dan Pengabdian Masyarakat Universitas Muhammadiyah Pekajangan Pekalongan}

\section{Pendahuluan}

Pada era sekarang kemudahan mengakses sebuah informasi mengenai obat sangatlah mudah, sehingga banyak masyarakat kemudian memilih melakukan tindakan pengobatan sendiri atau swamedikasi. Swamedikasi merupakan pengobatan sendiri terhadap suatu penyakit atau gejala yang ringan dilakukan dengan obat kimiawi maupun obat tradisional yang dapat dibeli tanpa menggunakan resesp dari dokter (Simbara et al, 2019).

Swamedikasi dapat terbentuk dari berbagai macam proses antara lain melalui proses interaksi antara manusia dengan lingkungan sekitar. Beberapa faktor yag bisa berpengaruh dalam terbentuknya perilaku swamedkasi antara lain faktor internal yaitu pengetahuan yang dimiliki, tingkat kecerdasan seseorang,serta persepi seseorang. Untuk faktor eksternal diantaranya pengaruh dari iklan baik televisi maupun media lainnya (Yusrizal, 2015)

Di Indonesia perilaku pengobatan sendiri (swamedikasi) memiliki nilai yang cukup besar.Perilaku swamedikasi salah satunya ditandai dengan menyimpan obatobatan pada rumah tangga untuk pengobatan diri sendiri. Data sebesar 35,2\% menunjukkan rumah tangga telah menyimpan obat untuk swamedikasi, diantaranya terdapat obat bebas, obat keras, serta obat-obat tradisional. Penggunaan obat keras dalam swamedikasi menunjukkan adanya penggunaan obat yang tidak rasional (Riskesdas, 2013).

Berdasarkan data dari World Health Organization (WHO) pada tahun 2018 angka kejadian dismenore di dunia sangat tinggi, rata-rata insiden disminore $16,8-81 \%$ perempuan remaja disetiap negara mengalami nyeri menstruasi (dismenore), seperti di Swedia dan Amerika Serikat angka yang ditunjukan yaitu diatas $70 \%$ wanita mengalami dismenore ringan hingga berat, bahkan menurut survei disminore merupakan salah satu penyebab paling sering ketidakhadiran disekolah yang dialami para remaja putri (Chayati, 2019).

Dismenore adalah kondisi dimana timbulnya rasa sakit dan tidak nyaman pada bagian perut dari mulai perut hingga bawah yang sakitnya terkadang bisa meluas sampai pinggang dan paha (Mulyani, 2012).Kebanyakan wanita mengalami rasa nyeri paling berat pada awal masa haid dan disertai mual, nyeri kepala dan payudara, gelisah dan mudah tersinggung. Dari hasil penelitian sebelumnya, yaitu oleh Purba,dkk tahun 2013 tentang hubungan pengetahuan dan perilaku penanganan dismenore pada SMA hasil didapatkan remaja putri terbanyak memiliki pengetahuan kurang sebanyak $54,5 \%$ dan perilaku penanganan dismenore kurang sebanyak $50,0 \%$ nilai probabilitas 0,00 .

Beberapa penelitian tentang swamedikasi di kalangan siswa jarang dilakukan. Namun, karena dibekali oleh ilmu pengetahuan dan kemudahan akses informasi pada saat ini, siswa terkadang mengatasi masalah kesehatan tersebut dengan cara swamedikasi, seperti yang telah dijelaskan pada penelitian sebelumnya. Penelitian yang dilakukan Sandra tahun 2015 juga mengatakan perlu adanya perlakuan lebih lanjut dari pihak instansi maupun terkait guna meningkatkan pengetahuan remaja mengenai penanganan dismenore. Oleh karena itu dilakukan penelitian 


\section{Prosiding Seminar Nasional Kesehatan Lembaga Penelitian dan Pengabdian Masyarakat Universitas Muhammadiyah Pekajangan Pekalongan

mengenaitingkat pengetahuan dan perilaku swamedikasi nyeri menstruasi(dismenore) pada siswi SMAN 1 Kajen Kabupaten Pekalongan.

\section{Metode}

A. Jenis penelitian

Penelitian ini merupakan penelitian deksriptif dengan menggunakan teknik purpose sampling dalam pangambilan.Pemilihan sekelompok subjek dalam purpose sampling didasarkan kriteria inklusi yaitu sampel yang dapat dimasukkan atau layak untuk diteliti. Intrumen penelitian yang digunakan adalah kuesioner sebagai alat pengukur data dan menggunakan metode cross sectional.

B. Populasi

Populasi merupakan wilayah generalisasi yang terdiri atas objek atau subjek yang mempunyai kualitas dan karakteristik tertentu yang ditetapkan oleh peneliti untuk dipeajari dan kemudian ditarik kesimpulannya.Adapun populasi dalam penelitian ini yaitu siswi jurusan IPS dan Bahasa di SMAN 1 Kajen Kabupaten Pekalongan Tahun 2021.

C. Sampel

Dalam penelitian ini sampel yang digunakan adalah siswi SMAN 1 Kajen Kabupaten Pekalongan jurusan IPS dan Bahasa dari kelas 1 sampai kelas 2 yang aktif pada tahun 2020/2021 dengan jumlah siswi 235 siswi dan penelitian ini dihitung dengan menggunakan rumus Slovin yang dikemukan oleh Umar (2013) sebagai berikut :

$$
\begin{aligned}
& \mathbf{n}=\mathbf{N} / \mathbf{1}+\mathbf{N e}^{\mathbf{2}} \\
& \text { Keterangan: } \mathrm{n}=\text { jumlah sampel } \\
& \begin{aligned}
\mathrm{N} & =\text { jumlah populasi } \\
\mathrm{e} & =\text { batas toleransi kesalahan (error tolerance) } \\
\mathrm{n} & =235 /\left(1+235.0,05^{2}\right) \\
& =235 /(1+0,5875) \\
& =235 / 1,5875 \\
& =148+10 \% \\
\mathrm{n} & =162
\end{aligned}
\end{aligned}
$$

D. Pengambilan dan Analisis Data

Sumber data dalam penelitian yaitu data primer yang diperoleh secara langsung dari responden dengan jumlah 162 siswi melalui pengisian kuesioner.Dalam penelitian ini terdapat 2 kuesioner yaitu tentang tingkat pengetahuan dan perilaku swamedikasi nyeri menstruasi (dismenore).Kuesioner yang digunakan sebelumnya dilakukan uji validitas dan uji reliabilitas dengan responden siswi SMAN 1 Bojong Kabupaten Pekalongan. Data diolah menggunakan Statistical Package For the Sosial Science (SPSS) versi 16, kemudian analisis data dilakukan 2 tahap yaitu analisis univariat untuk 


\section{Prosiding Seminar Nasional Kesehatan $\mid 2021$ Lembaga Penelitian dan Pengabdian Masyarakat Universitas Muhammadiyah Pekajangan Pekalongan}

mendapatkan gambaran distribusi frekuensi karakteristik demografi dan variabel lain. Analisis bivariat digunakan untuk mengetahui hubungan antara tingkat pengetahuan terhadap perilaku swamedikasi nyeri mesntruasi (dismenore) menggunakan uji korelasi spearman rank.

\section{Hasil dan Pembahasan}

Hasil

\section{A. Karakteristik Responden}

Berdasarkan data yang diperoleh dari data primer kuesioner yang diperoleh langsung dari responden yaitu siswi SMAN 1 Kajen Kabupaten Pekalongan jurusan IPS dan Bahasa dengan jumlah 162 siswi melalui pengisian kuesioner.

Tabel 1. Hasil Distribusi Berdasarkan Usia

\begin{tabular}{cccc}
\hline No & Usia & Jumlah & $\begin{array}{c}\text { Persentase } \\
(\%)\end{array}$ \\
\hline 1 & $10-12$ tahun & 0 & 0 \\
2 & $13-15$ tahun & 44 & 27 \\
3 & $16-18$ tahun & 104 & 64 \\
4 & $19-21$ tahun & 14 & 9 \\
\hline Jumlah & & 162 & 100 \\
\hline
\end{tabular}

Pada tabel.1 memperlihatkan bahwa berdasarkan data karakteristik responden sebagian besar responden yang mengalami dismenore terjadi pada responden usia antara 16-18 tahun yaitu sebanyak 104 responden (64\%).

Tabel 2. Hasil BMI Responden

\begin{tabular}{cccc}
\hline No & BMI & Jumlah & $\begin{array}{c}\text { Persentase } \\
(\%)\end{array}$ \\
\hline 1 & Kurus & 39 & 24 \\
2 & Normal & 108 & 67 \\
3 & Gemuk & 15 & 9 \\
\hline Jumlah & & 162 & 100 \\
\hline
\end{tabular}

Berdasarkan Tabel.2 memperlihatkan bahwa sebagian responden termasuk dalam kategori BMI (Body Mass Index) yang normal yaitu sebanyak 108 responden (67\%). Sebanyak 39 responden (24\%) masuk dalam kategori BMI kurus dan sebanyak 15 (9\%) masuk dalam kategori BMI gemuk.

Tabel 3. Alasan Swamedikasi Nyeri Menstruasi (Dismenore)

\begin{tabular}{clcc}
\hline No & \multicolumn{1}{c}{ Pernyataan } & Jumlah & $\begin{array}{c}\text { Persentase } \\
(\%)\end{array}$ \\
\hline 1 & Gejala dismenore yang & 40 & 25 \\
& dialami & 33 & 20 \\
2 & Tidak suka pergi ke dokter & 57 & 35 \\
3 & Cepat dan praktis & 4 & 3 \\
4 & Lebih murah & 28 & 17 \\
5 & Lainnya & & \\
\hline
\end{tabular}




\section{Prosiding Seminar Nasional Kesehatan Lembaga Penelitian dan Pengabdian Masyarakat Universitas Muhammadiyah Pekajangan Pekalongan

Berdasarkan Tabel.3 menunjukkan bahwa alasan terbanyak yang dipilih responden untuk melakukan swamedikasi nyeri menstruasi (dismenore) yaitu sebanyak 57 responden (35\%) memilih alasan cepat dan praktis.

Tabel 4. Tindakan Swamedikasi yang Dilakukan Responden

\begin{tabular}{clcc}
\hline No. & \multicolumn{1}{c}{ Pernyataan } & Jumlah & $\begin{array}{c}\text { Persentase } \\
(\%)\end{array}$ \\
\hline 1 & Minum obat & 26 & 16 \\
2 & Tidur & 55 & 34 \\
3 & Kompres dengan air & 61 & 38 \\
& $\begin{array}{l}\text { hangat bagian perut dan } \\
\text { pinggang }\end{array}$ & & \\
4 & Minum obat herbal / jamu & 10 & 6 \\
5 & Memijat pinggang & 5 & 3 \\
6 & Lainnya & 5 & 3 \\
\hline
\end{tabular}

Pada Tabel.4 menunjukkan tindakan swamedikasi yag dilakukan responden dalam melakukan swamedikasi nyeri menstruasi (dismenore) yaitu sebagian besar sebanyak 61 responden (38\%) memilih megkompres dengan air hangat pada bagian perut dan pinggang, sedangkan responden paling sedikit sebanyak 5 responden $(3 \%)$ memilih memijat pinggang.

Tabel 5. Tempat Mendapatkan Obat Pada Swamedikasi

\begin{tabular}{clcc}
\hline No & \multicolumn{1}{c}{ Pernyataan } & Jumlah & $\begin{array}{c}\text { Persentase } \\
(\%)\end{array}$ \\
\hline 1 & Toko / warung klontong & 11 & 7 \\
2 & Toko obat & 5 & 3 \\
3 & Apotek & 104 & 64 \\
4 & Minimarket & 8 & 5 \\
5 & Lainnya & 34 & 21 \\
\hline
\end{tabular}

Pada Tabel.5 menunjukkan tempat mendapatkan obat pada swamedikasi yaitu sebagian besar responden sebanyak 104 responden (64\%) memilih apotek sebagai tempat mendapatkan obat pada swamedikasi nyeri menstruasi (dismenore).

Tabel 6. Asal Informasi Penggunaan Obat Pada Swamedikasi

\begin{tabular}{clcc}
\hline No & \multicolumn{1}{c}{ Pernyataan } & Jumlah & $\begin{array}{c}\text { Persentase } \\
(\%)\end{array}$ \\
\hline 1 & Leaflet / kemasan obat & 47 & 28,5 \\
2 & Pengalaman & 19 & 12,7 \\
3 & Petugas apotek & 64 & 38,8 \\
4 & Lainnya & 32 & 20 \\
\hline
\end{tabular}

Pada penelitian ini diketahui bahwa mayoritas responden melakukan swamedikasi berdasarkan informasi dari petugas apotek dengan persentase $38,8 \%$. Data lengkap dapat di lihat pada Tabel.6. 


\section{Prosiding Seminar Nasional Kesehatan Lembaga Penelitian dan Pengabdian Masyarakat Universitas Muhammadiyah Pekajangan Pekalongan

Tabel 7. Tindakan Apabila Swamedikasi Tidak Berhasil

\begin{tabular}{clcc}
\hline No & \multicolumn{1}{c}{ Pernyataan } & Jumlah & $\begin{array}{c}\text { Persentase } \\
(\%)\end{array}$ \\
\hline 1 & Mengganti obat & 10 & 6 \\
2 & Beralih ke pengobatan & 8 & 5 \\
& alternatif & & 72 \\
3 & Pergi ke dokter & 117 & 17 \\
4 & Di biarkan saja & 27 & \\
\hline
\end{tabular}

Pada penelitian ini diketahui tindakan swamedikasi yang dilakukan jika tidak berhasil yaitu sebanyak 117 responden (72\%) yang merupakan mayoritas memilih pergi ke dokter. Data lengkap dapat di lihat pada Tabel.7

Tabel. 8 Distribusi Berdasarkan Jurusan

\begin{tabular}{clcc}
\hline No & Jurusan & Jumlah & $\begin{array}{c}\text { Persentase } \\
(\%)\end{array}$ \\
\hline 1 & IPS & 118 & 73 \\
2 & Bahasa & 44 & 27 \\
\hline Jumlah & & 162 & 100 \\
\hline
\end{tabular}

Dari Tabel. 8 dapat diketahui distribusi jumlah responden dari jurusan IPS dan Bahasa. Jumlah persentase dari jurusan IPS yaitu sebanyak $73 \%$ dengan jumlah siswi 118 dan dari jurusan Bahasa sebanyak 27\% dengan jumlah siswi 44 . Pada penelitian ini responden terbanyak dari jurusan IPS dengan jumlah responden 118 dikarenakan jumlah siswi yang banyak dan tersebar di 4 kelas disetiap angakatannya. Sedangkan responden yang berasal dari jurusan Bahasa sebanyak 44 responden dikarenakan siswi untuk jurusan Bahasa sedikit dan mempunyai 1 kelas disetiap angkatannya

Tabel 9. Distribusi Frekuensi Kuesioner Pengetahuan

\begin{tabular}{|c|c|c|c|c|c|c|}
\hline \multirow{2}{*}{ No } & \multirow{2}{*}{\multicolumn{2}{|c|}{ Pertanyaan }} & \multicolumn{4}{|c|}{ Frekuensi } \\
\hline & & & $\begin{array}{c}\text { Jawaban } \\
\text { Ya }\end{array}$ & $\begin{array}{c}\text { Persentase } \\
(\%)\end{array}$ & $\begin{array}{c}\text { Jawaban } \\
\text { Tidak }\end{array}$ & $\begin{array}{c}\text { Persentase } \\
(\%)\end{array}$ \\
\hline \multirow[t]{3}{*}{1} & a. & $\begin{array}{l}\text { Suatu kegiatan yang } \\
\text { dilakukan } \begin{array}{r}\text { untuk } \\
\text { mengobati dirisendiri }\end{array} \\
\text { disebut swamedikasi }\end{array}$ & 159 & 98 & 3 & 2 \\
\hline & b. & $\begin{array}{l}\text { Swamedikasi hanya } \\
\text { untuk penyakit yang } \\
\text { ringan saja seperti } \\
\text { demam, nyeri haid, diare } \\
\text { dan batuk }\end{array}$ & 132 & 81 & 30 & 19 \\
\hline & C. & $\begin{array}{l}\text { Swamedikasi nyeri } \\
\text { menstruasi bisa dilakukan } \\
\text { dengan obat-obat } \\
\text { kimiawi danobat } \\
\text { tradisional yang dibeli } \\
\text { tanpa resep dokter }\end{array}$ & 121 & 75 & 41 & 25 \\
\hline
\end{tabular}




\section{Prosiding Seminar Nasional Kesehatan Lembaga Penelitian dan Pengabdian Masyarakat Universitas Muhammadiyah Pekajangan Pekalongan}

\begin{tabular}{|c|c|c|c|c|c|c|}
\hline \multirow[b]{2}{*}{ No } & & \multirow{2}{*}{ Pertanyaan } & \multicolumn{4}{|c|}{ Frekuensi } \\
\hline & & & $\begin{array}{c}\text { Jawaban } \\
\text { Ya }\end{array}$ & $\begin{array}{c}\text { Persentase } \\
(\%)\end{array}$ & $\begin{array}{l}\text { Jawaban } \\
\text { Tidak }\end{array}$ & $\begin{array}{c}\text { Persentase } \\
(\%)\end{array}$ \\
\hline 2 & a. & $\begin{array}{l}\text { Menstruasi atau haid } \\
\text { merupakan peristiwa } \\
\text { perdarahan bulanan }\end{array}$ & 157 & 97 & 5 & 3 \\
\hline & b. & $\begin{array}{lr}\text { Menstruasi } & \text { merupakan } \\
\text { kejadian } & \text { yang } \\
\text { menakutkan } & \end{array}$ & 151 & 93 & 11 & 7 \\
\hline & c. & $\begin{array}{l}\text { Faktor kejiwaan atau } \\
\text { stress merupakan salah } \\
\text { satu penyebab dismenore } \\
\text { primer }\end{array}$ & 110 & 68 & 52 & 32 \\
\hline 3 & a. & $\begin{array}{l}\text { gejala-gejala seperti } \\
\text { mual, muntah, diare, } \\
\text { sakit kepala dan mudah } \\
\text { tersingung merupakan } \\
\text { gejala nyei haid }\end{array}$ & 142 & 88 & 20 & 12 \\
\hline & b. & \begin{tabular}{lr}
\multicolumn{2}{c}{ dismenore merupakan } \\
tanda gejala adanya \\
penyakit pada organ \\
reproduksi
\end{tabular} & 139 & 86 & 23 & 14 \\
\hline & c. & $\begin{array}{l}\text { Apakah dengan } \\
\text { mengkonsumsi makanan } \\
\text { sehat dan istirahat cukup } \\
\text { dapat mengurangi nyeri } \\
\text { menstruasi (dismenore)? }\end{array}$ & 159 & 98 & 3 & 2 \\
\hline
\end{tabular}

Berdasarkan dari seluruh jawaban yang diperoleh dari responden diketahui bahwa sebagian besar responden menjawab dengan baik mengenai tingkat pengetahuan. Mayoritas responden menjawab dengan baik mengenai definisi dari swamedikasi (98\%) dan usaha untuk mengurangi nyeri menstruasi (98\%). Tetapi responden paling sedikit menjawab pertanyaan dengan baik mengenai faktor penyebab nyeri menstruasi $(68 \%)$.

Tabel 10. Distribusi Frekuensi Kuesioner Perilaku

\begin{tabular}{|c|c|c|c|c|c|c|}
\hline \multirow[b]{2}{*}{ No } & \multirow{2}{*}{\multicolumn{2}{|c|}{ Pertanyaan }} & \multicolumn{4}{|c|}{ Frekuensi } \\
\hline & & & $\begin{array}{c}\text { Jawaban } \\
\text { Ya }\end{array}$ & $\begin{array}{c}\text { Persenta } \\
\text { se } \\
(\%)\end{array}$ & $\begin{array}{c}\text { Jawab } \\
\text { an } \\
\text { Tidak }\end{array}$ & $\begin{array}{c}\text { Persentase } \\
(\%)\end{array}$ \\
\hline 1 & a. & $\begin{array}{lr}\text { Mengatasi } & \text { nyeri } \\
\text { menstruasi } & \text { hanya } \\
\text { dengan } & \text { istrahat } \\
\text { (tidur) } & \end{array}$ & 80 & 49 & 82 & 51 \\
\hline & b. & $\begin{array}{l}\text { Selalu minum obat } \\
\text { ketika mengalami } \\
\text { nyeri menstruasi } \\
\text { (dismenore) }\end{array}$ & 18 & 11 & 144 & 89 \\
\hline & c. & $\begin{array}{l}\text { Mengatasi nyeri } \\
\text { menstruasi } \\
\text { (dismenore) dengan } \\
\text { minum obat } \\
\text { traidisional }\end{array}$ & 84 & 52 & 78 & 48 \\
\hline
\end{tabular}




\section{Prosiding Seminar Nasional Kesehatan Lembaga Penelitian dan Pengabdian Masyarakat Universitas Muhammadiyah Pekajangan Pekalongan}

\begin{tabular}{|c|c|c|c|c|c|c|}
\hline \multirow[b]{2}{*}{ No } & \multirow{2}{*}{\multicolumn{2}{|c|}{ Pertanyaan }} & \multicolumn{4}{|c|}{ Frekuensi } \\
\hline & & & $\begin{array}{c}\text { Jawaban } \\
\text { Ya }\end{array}$ & $\begin{array}{c}\text { Persenta } \\
\text { se } \\
(\%)\end{array}$ & $\begin{array}{c}\text { Jawab } \\
\text { an } \\
\text { Tidak }\end{array}$ & $\begin{array}{l}\text { Persentase } \\
\quad(\%)\end{array}$ \\
\hline 2 & a. & $\begin{array}{l}\text { Selalu minum obat } \\
\text { ketika mengalami } \\
\text { nyeri menstruasi } \\
\text { (dismenore) }\end{array}$ & 96 & 59 & 66 & 41 \\
\hline & b. & $\begin{array}{l}\text { Meminum obat ketika } \\
\text { terasa nyeri saja }\end{array}$ & 144 & 89 & 18 & 11 \\
\hline & c. & $\begin{array}{l}\text { Obat yang diminum } \\
\text { merupakan } \\
\text { analgetik(anti nyeri) }\end{array}$ & 106 & 65 & 56 & 35 \\
\hline 3 & a. & $\begin{array}{l}\text { Selalu membaca } \\
\text { informasi pada } \\
\text { kemasan obat yang } \\
\text { akan diminum }\end{array}$ & 158 & 98 & 4 & 2 \\
\hline & b. & $\begin{array}{l}\text { Menghentikan minum } \\
\text { obat ketika muncul } \\
\text { efek lain, seperti } \\
\text { mual dan pusing }\end{array}$ & 150 & 93 & 12 & 7 \\
\hline & c. & $\begin{array}{l}\text { Meminum obat lain } \\
\text { (selain anti nyeri) } \\
\text { secara bersamaan }\end{array}$ & 161 & 99 & 1 & 1 \\
\hline
\end{tabular}

Berdasarkan dari seluruh jawaban yang diperoleh dari responden diketahui bahwa sebagian besar responden menjawab dengan baik mengenai perilaku swamedikasi nyeri menstuasi (dismenore). Mayoritas responden menjawab dengan baik mengenai tindakan tidak minum obat anti nyeri lain secara bersamaan (99\%) dan mengenai tindakan selalu membaca informasi pada kemasan obat (98\%).

Tabel. 11 Analisa Univariat Pengetahuan

\begin{tabular}{lccc}
\hline \multicolumn{2}{c}{ Tingkat Pengetahuan } & Frekuensi & $\begin{array}{c}\text { Persentase } \\
(\%)\end{array}$ \\
\hline Valid & Cukup & 2 & 1,2 \\
& Baik & 50 & 30,9 \\
& Sangat Baik & 110 & 67,9 \\
\hline & Total & 162 & 100 \\
\hline
\end{tabular}

Berdasarkan Tabel.11 diketahui terdapat 2 responden (1,2\%) memiliki tingkat pengetahuan cukup, sebanyak 50 responden $(30,9 \%)$ memiliki tingkat pengetahuan baik dan 110 responden (67,9\%) memiliki tingkat pengetahuan sangat baik. Hal tersebut menunjukkan bahwa mayoritas responden memiliki tingkat pengetahuan sangat baik tentang swamedikasi nyeri mesntruasi (dismenore).

Tabel 12. Analisa Univariat Perilaku

\begin{tabular}{lccc}
\hline & Tingkat Perilaku & Frekuensi & $\begin{array}{c}\text { Persentase } \\
(\%)\end{array}$ \\
\hline Valid & Cukup & 39 & 24,1 \\
& Baik & 111 & 68,5 \\
& Sangat Baik & 12 & 7,4 \\
\hline & Total & 162 & 100 \\
\hline
\end{tabular}




\section{Prosiding Seminar Nasional Kesehatan 2021 \\ Lembaga Penelitian dan Pengabdian Masyarakat Universitas Muhammadiyah Pekajangan Pekalongan}

Berdasarkan Tabel.12 diketahui sebanyak 39 responden $(24,1 \%)$ memiliki perilaku cukup, sebanyak 111 responden (58,5\%) memiliki perilaku baik dan sebanyak 12 responden $(7,4 \%)$ memiliki perilaku sangat baik. Hal tersebut menunjukkan bahwa mayoritas responden memiliki perilaku swamedikasi nyeri menstruasi (dismenore) yang baik.

Tabel 13. Uji Tabulasi Silang

\begin{tabular}{cccc}
\hline Variabel Penelitian & & Perilaku & \\
& & & \\
& & cukup & baik \\
& Sangat Baik & & 0 \\
PengetahuanCukup & 2 & 0 & $.0 \%$ \\
& $100 \%$ & $.0 \%$ & 0 \\
Baik & 14 & 36 & $.0 \%$ \\
& $28.0 \%$ & $72.0 \%$ & 12 \\
& 23 & 111 & $7.4 \%$ \\
\hline
\end{tabular}

Dilihat melalui tabel silang pada Tabel.13 menunjukkan bahwa pada siswi yang memiliki tingkat pengetahuanSangat Baik dengan perilaku baik $(68,2 \%)$, memiliki tingkat pengetahuan perilaku swamedikasi nyeri menstruasi yang sangat baik $(10,9 \%)$, sedangkan pada siswi yang memiliki tingkat pengetahuan cukup dengan perilaku swamedikasi nyeri menstruasi kategori cukup juga (100\%).

Tabel 14. Uji Spearman Rank

\begin{tabular}{lcc}
\hline Spearman's rho & Korelasi Nilai $r$ & $P$ value \\
\hline - Tingkat pengetahuan & & \\
- Perilaku & 0,184 & 0,019 \\
\hline
\end{tabular}

Berdasarkan hasil analisis statistik dengan menggunakan uji Spearman Rank didapatkan nilai $\rho$ value sebesar $0,019(<0,05)$ sehingga Ho ditolak, dapat disimpulkan bahwa ada hubungan yang signifikan antara tingkat pengetahuan terhadap perilaku swamedikasi nyeri menstruasi (dismenore) pada siswi jurusan IPS dan Bahasa di SMAN 1 Kajen Kabupaten Pekalongan. Nilai korelasi Spearman ( $r$ ) sebesar 0,184

\section{Pembahasan}

Berdasarkan dari data karakteristik responden.Jumlah responden paling banyak berdasarkan usia yaitu 16-18 tahun yang dimana usia tersebut merupakan usia remaja yang duduk di Sekolah Menegah Atas yang sering mengalami nyeri menstruasi, salah satu faktor yang mempengaruhi adalah faktor usia dengan pengetahuan dan perilaku yang membuktikan bahwa dugaan usia dapat menjadi faktor dilakukannya perilaku swamedikasi secara rasional dan tepat. Menurut Wahyuni (2014) juga menyatakan bahwa pada periode umur tersebut merupakan masa akhir dimana tahap ini adalah 


\section{Prosiding Seminar Nasional Kesehatan 2021 Lembaga Penelitian dan Pengabdian Masyarakat Universitas Muhammadiyah Pekajangan Pekalongan}

masa berfikir khayal pada remaja sehingga dibutuhkan pengarahan mengenai masalah dismenore, pada umur ini tergolong umur yang masih muda yang dimana pada penelitian yaitu 13-21 tahun menurut WHO masih tergolong dalam kelompok remaja sehingga masih tinggi tingkat dismenore.

Berdasarkan Pada karakteristik respoden didapatkan hasil responden besar mempunyai Body Mass Index (BMI) yang normal. Menurut Rafia,dkk (2017) dan Akshara (2015) pada penelitiannya juga mendapat hasil yang serupa. BMI merupakan alat yang sederhana untuk memantau status gizi orang, khususnya yang berkaitan dengan kekurangan dan kelebihan berat badan.

Status gizi lebih dikatakan dapat menyebabkan dismenore karena seseorang yang memiliki berat badan lebih akan memiliki jaringan yang berlebih pula yang membuat pembuluh darah pada organ reproduksi wanita mengalami hiperplasi dan dapat menimbulkan dismenore. Status gizi rendah juga dapat mengakibatkan dismenore dikarenakan kurangnya asupan makanan, termasuk asupan zat besi yang dapat mengakibatkan daya tahan tubuh terhadap rasa nyeri menjadi menurun sehingga timbulnya dismenore saat menstruasi (Amita dkk, 2018).

Terdapat ketidaksesuaian antara hasil penelitian dengan teori yang ada, hal ini terjadi karena status gizi bukan merupakan satu-satunya faktor yang mempengaruhi dismenore.Sebagian besar pada penelitian ini memiliki BMI normal sehingga terlihat bahwa sebagian besar responden yang mengalami dismenore memiliki BMI normal.Selain itu, variasi ini juga dapat disebabkan karena perbedaan proporsi antara responden yang memiliki BMI normal dengan BMI kurang atau lebih.

Pada profil data karakteristik selanjutnya adalah alasan melakukan swamedikasi nyeri menstruasi (dismenore), hal ini sangat mendasar mengingat swamedikasi merupakan pilihan pengobatan sendiri selain ke dokter.Apapun alasannya, namun tujuan utamanya adalah untuk terapi agar sembuh dari gejala atau penyakit yang di derita. Sebagian besar responden memilih cepat dan praktis sebagai alasan melakukan swamedikasi nyeri menstruasi (dismenore) Hasil tersebut berbeda dengan penelitian yang dilakuakn oleh Rizkiyah (2014) terhadap 380 mahasiswa Universitas Sumatera Utara menunjukkan alasan pengobatan murah yang paling banyak dipilih kedua setelah pengalaman penggunaan obat sesbelumnya sebagai alasan melakukan swamedikasi.

Berdasarkan data karakteritik responden mengenai tindakan swamedikasi yang dilakukan untuk mengurangi gejala nyeri menstruasi (dismenore) menunjukkan bahwa sebagian besar esponden melakukan swamedikasi dengan mengkompres bagian perut dan pinggang dengan air hangat (38\%) dan tidur/ istirahat (34\%). Hasil tersebut sesuai dengan penelitian oleh Erlina (2014) yang menyatakan bahwa tindakan non famakologi yang dilakukan untuk mengurangi nyeri haid dan Nugroho (2014) yang menyatakan bahwa selain dengan obat-obatan rasa nyeri akibat menstruasi (dismenore) juga bisa dikurangi salah satunya dengan istirahat yang cukup.

Analisa univariat pada penelitian ini bertujuan untuk menjelaskan atau mendeskripsikan karakteristik masing-masing variabel yang diteliti.Berdasarkan Tabel.11diketahui bahwa mayoritas responden memiliki tingkat pengetahuan sangat baik tentang swamedikasi nyeri mesntruasi (dismenore). Dan Berdasarkan Tabel.12 


\section{Prosiding Seminar Nasional Kesehatan Lembaga Penelitian dan Pengabdian Masyarakat Universitas Muhammadiyah Pekajangan Pekalongan}

diketahui bahwa mayoritas responden memiliki perilaku swamedikasi nyeri menstruasi (dismenore) yang baik.

Berdasarkan hasil analisis statistik dengan menggunakan uji Spearman Rank didapatkan nilai $\rho$ value sebesar $0,019(<0,05)$ sehingga Ho ditolak, dapat disimpulkan bahwa ada hubungan yang signifikan antara tingkat pengetahuan terhadap perilaku swamedikasi nyeri menstruasi (dismenore) pada siswi jurusan IPS dan Bahasa di SMAN 1 Kajen Kabupaten Pekalongan. Nilai korelasi Spearman ( $r$ ) sebesar 0,184 menunjukkan bahwa kekuatan hubungan yang lemah dan karena nilai korelasi $r$-nya (+) positif maka arah korelasinya searah artinya semakin tinggi tingkat pengetahuan diikuti semakin tinggi perilaku swamedikasi nyeri menstruasi (dismenore) pada siswi jurusan IPS dan Bahasa di SMAN 1 Kajen Kabupaten Pekalongan, begitu juga sebaliknya.

\section{Kesimpulan}

Berdasarkan hasil dan pembahasan mengenai Hubungan Tingkat Pengetahuan Terhadap Perilaku Swamedikasi Nyeri Mnestruasi (Dismenore) Pada Siswi SMAN 1 Kajen Kabupaten Pekalongan Tahun 2021, maka dapat disimpulkan bahwa Pada tingkat pengetahuan diketahui terdapat 2 responden $(1,2 \%)$ memiliki tingkat pengetahuan cukup, sebanyak 50 responden (30,9\%) memiliki tingkat pengetahuan baik dan 110 responden $(67,9 \%)$ memiliki tingkat pengetahuan sangat baik. Hal tersebut menunjukkan bahwa mayoritas responden memiliki tingkat pengetahuan sangat baik tentang swamedikasi nyeri mesntruasi (dismenore). Pada perilaku responden diketahui sebanyak 39 responden $(24,1 \%)$ memiliki perilaku cukup, sebanyak 111 responden (58,5\%) memiliki perilaku baik dan sebanyak 12 responden $(7,4 \%)$ memiliki perilaku sangat baik. Hal tersebut menunjukkan bahwa mayoritas responden memiliki perilaku swamedikasi nyeri menstruasi (dismenore) yang baik.

\section{Referensi}

[1]. Bano Rafia, AlShammari E, Aldeabani HKS.Study of the Prevalence and Severity of Dysmenorrhea among the University Students of Hail City. International Journal of Health Sciences \& Research. 3(10): 15-22. 2013

[2]. Harahap, N. A. Tingkat Pengetahuan dan Rasionalitas Swamedikasi di Tiga Apotek Kota Penyambungan. Skripsi. Medan: Fakultas Farmasi Universitas Sumatera Utara. 2015.

[3]. Hidayati, Herdaru Dyah. Tingkat Pengetahuan Dan Tindakan SwamedikasiDiare Pada Pelajar SMA Negeri 1 Karanganom Kecamatan Karanganom Kabupaten Klaten.Skripsi.Universitas Muhammadiyah Surakarta. 2012.

[4]. Mathew A, Varghese Dm, Shaju MV, Joseph N, Tamrakar A. Dysmenorrhea among Adsolescent Grils in Selected Schols at Mangalore with view to Develop and Dsitribute an Information Booklet . IOSR Journal Nursing and Healt Science. 2015 . 4(1) : 34.

[5]. Mulyani, S. Tingkat Pengetahuan Remaja Putri Tentang Dismenorea Kelas VIII diSMPN 1 Kedawung Sragen, Sekolah Tinggi Ilmu Kesehatan Kusuma Husada, Sragen. 2012. 


\section{Prosiding Seminar Nasional Kesehatan 2021 Lembaga Penelitian dan Pengabdian Masyarakat Universitas Muhammadiyah Pekajangan Pekalongan}

[6]. Nugroho , T., Warnaliza, D. Buku ajar asuhan kebidanan nifas (askeb 3). Yogyakarta :Nuha Medika. 2014.

[7]. Sandra B Ghozali. Gambaran Pengetahuan Remaja Putri Mengenai PenangananDismenorea Kelurahan Kedungwinong, Surakarta. Skripsi.Fakultas Ilmu Kesehatan Universitas Muhammadiyah Surakarta. 2015.

[8]. Simbara, Ari., Primananda, A.Z., Tetuko, A., Savitri, C.N. Edukasi Gerakan MasyarakatCerdas Menggunakan Obat (Gema Cermat)

Untuk meningkatkan Pengetahuan Swamedikasi. Indonesia Jurnal Farmasi. 2019.Vol. 4 No.1.

[9]. Purba, E. P. N., Rompas, S., dan Karundeng, M. Hubungan Pengetahuan DenganPerilaku Penanganan Dismenore Di SMA Negeri 7 Manado. Jurnal Kesehatan. UniversitasSam Ratulangi Manado. 2014.

[10]. Riskesda. Riset Kesehatan Dasar. Jakarta: Badan Penelitian dan Pengembangan Kesehatan Kementrian Kesehatan RI. 2016.

[11]. Rochmawati, Anis. Swamedikasi Di Kalangan Mahasiswa Kesehatan Dan Non Kesehatan Di Universitas Jember.Jember: Universitas Jember. 2016.

[12]. Rustam Erlina. Gambaran Pengetahuan Remaja Puteri Terhadap Nyeri Haid(Dismenore) dan Cara Penanggulangannya. Jurnal Kesehatan Andalas. 2014.

[13]. Umar, Husein. Metode Penelitian Untuk Skripsi dan Tesis Bisnis.Jakarta : PT Raja Grafindo Persada. 2013.

[14]. Wahyuni, Romy. 2014. Faktor-Faktor yang Berhubungan dengan Nyeri Menstruasi (Dismenorea) pada Remaja Putri di BeberapaSMA di Kabupaten Rokan Hulu. Jurnal Maternity and Neonatal Volume 1. Universitas Pasir Pengaraian. 2014.

[15]. Yusrizal, Y. Gambaran Peggunaan Obat Dalam Upaya Swamedikasi Pada Pengunjung Apotek Pandan Kecamatan Jati Agung Kabupaten Lampung SelatanTahun 2014. Jurnal Kesehatan.2015. Vol 4, No 2. 